\title{
Methodology of verification for risk the biocorrosion development in the layers of "Double ETICS".
}

\author{
Barbora Belániová $^{1, *}$, and Nad'a Antošová ${ }^{1}$ \\ ${ }^{1}$ Faculty of Civil Engineering in Bratislava, STU, Department of Building Technology, Radlinského \\ 11, 81005 Bratislava, Slovakia
}

\begin{abstract}
Anyhow renovation of the surfaces of building materials and structures without thorough disposal of biological material has not been proven in the past. The main topic of the paper is to find out the functionality of the new technology in terms of survival and development of biocorrosion in structures. The main focus of the thesis is verification the treatment of moisture composite "Double ETICS", the possible growth of microorganisms and the subsequent degradation of components. The aim of research is to propose a methodology for the verification of humidity and temperature conditions in the composite construction and development of microorganisms after application of alternative technology of preparation of the substrate under the technology "Double ETICS".
\end{abstract}

\section{Introduction}

External thermal insulation composite systems (ETICS) are often used throughout the world at present. Despite their thermal advantages, low cost and effortless of application, undesirable problems causing microbiological growth and damage to the cladding may appear on this system. According to several studies [1], the hygrothermal behaviour of the facade with applied technology was monitored. Joint influence of various factors, especially external factors, there is a defect - a biocorrosion that can affect to the lifespan of the construction. [2] Microbial activity can also have a significant impact on the durability of building materials not only on the insulation system.

Authors [3] describe how microorganisms can change properties, and what possible strategies are appropriate for treatment, repair and renovation of buildings. It is important to investigate the causes of algae and fungi growth to understand the hygrothermal behaviour of facades covered by the ETICS. Dynamic heat exchanges between the environment and building elements and temperature fluctuations of the wall surfaces caused by radiation are two important aspects that are to be considered according to [4].

The extermination and long-term prevention of surface colonization require immediate operational interventions and efficient technologies. In this context, knowledge of possible interventions has been gathered and verified. To remove microorganisms in contact thermal insulation systems in practice there are used to two basic technologies with different lifespan, financial and technical demands - conservative and radical.

\footnotetext{
*Corresponding author: barborabelaniova@gmail.com
} 


\section{Methodology of work}

The research is focused on innovative technology for renovation of built-in thermal insulation, additional thermal insulation of so "Double ETICS", which is a radical technology to remove the defect - biocorrosion. Basic research is specialized to obtaining the necessary theoretical assessments and localization of moisture in the composite structure as a possible source of water supply to residual microorganisms on the original surface of the ETICS. The main focus of the thesis is verification the threat of moisture in the composite "Double ETICS" structure for the possible development of microorganisms. The methodology of work consists in verifying these assumptions about the development of microorganisms in a long-term experiment in situ without necessity for a complicated simulation of the internal and external environment. As follows, authentic heat-humidity conditions are achieved in the construction of thermal insulation system. The results should be the basis for the design of the preparation base for "Double ETICS" technology in terms of the presence of biocorrosion in the composite of the original ETICS and the new additional thermal insulation construction.

\section{Risk of development of biocorrosion in the composite structure "Double ETICS"}

According to research [5-7] the formation, development and destructive influence of microorganisms on building materials have a direct impact on the living conditions for their existence. For the intensity of the algae growth on the façade, especially humidity, nutrients supply, $\mathrm{pH}$ of the environment and peripheral light are required. One of the most effective new solutions for solving microorganisms on the surface of thermal insulation systems could be technology to renovation the existing ETICS construction - "Double ETICS" technology. The "Double ETICS" design for the typical representative of thermal insulation apartment houses in Slovakia - the external cladding housing construction rack construction of the "Bauring-Camus T-BA-BC", was elaborated within the scope of basic research. The substance of duplication was the addition of a further thermal insulation layer, reinforcement layer and new plaster [8]. The new plaster is component of the solution to biocorrosion on the surface of the original ETICS and must therefore have new modified properties that reduce the risk of biological attack on the new ETICS surface.

Initially, it was necessary to perform an analysis of alternative solutions of thermal insulation layers in the double thermal insulation structure and to find out the differences in thermo-technical and moisture parameters of the double structure. The minimum thickness of the new thermal insulation according to $[8,9]$ is $50 \mathrm{~mm}$. Thermal insulation contact systems can be designed and built to meet the requirements $[9,10]$, and demonstrating their synergy with a system that duplicates [8]. Today's market offers various insulating materials that could be used in double insulation (MW, EPS, Polyurethane ..). However, the condition according to [11] must be fulfilled, where it is necessary to choose material with the same or better diffusion properties as the original thermal insulation. From the point of view of the distribution of the temperature field and the humidity regime in the insulation construction, a theoretical assessment of the new composite structure with all types of insulation was performed. In the case of finding the answers to the possibility of condensation in the double layer of thermal insulation, the values of the thermal field in the cross-section of the cladding were reconsidered and evaluated. The purpose of the assessment was to locate the moisture in the structure of the new construction. By simulating the most occurring realization of insulating board gluing and simulation of temperature ratios in Bratislava, possible critical locations for the creation of suitable moisture ratios for algae at the site of contact of the original and the new ETICS were 
recorded. The most critical moisture level in the stack was demonstrated in the foam polystyrene construction (Figure 1).

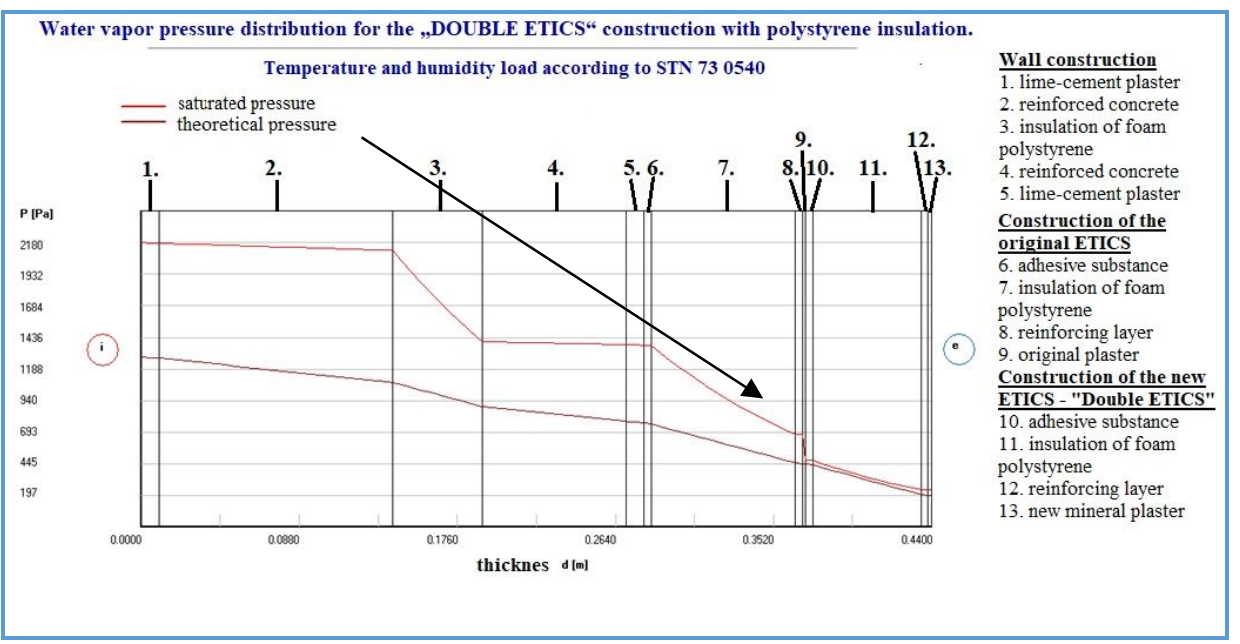

Fig. 1. Water vapor pressure distribution for the „DOUBLE ETICS“ construction with polystyrene insulation. Processed according to [12].

From these theoretical calculations it follows that in the ideal state of realization and adherence to all technological rules it is theoretically possible to create suitable humidity ratios for the risk of developing microorganisms between the original substrate and the new insulation. The theoretical creation of moisture in an appropriate structure was dealt with by authors [13]. They simulated the condensation of water vapor in the ETICS layout and found where the build-up of moisture could occur. To compare research results, they used different types and thicknesses of structures and thermal insulation.

The results of the investigations show that long-term accumulation of partial moisture in the double ETICS may occur. The moisture content of the insulating layers is significantly less than 2\% (Figure 2), and therefore at a level where no evidence of a reduction in the insulation effect can be expected. The worst results of the moisture ratios in the doubled structure were achieved with the use of resin-based plasters.

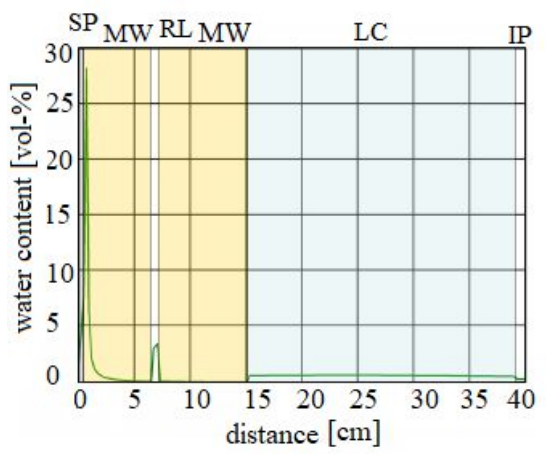

Fig. 2. Profile of the water content in the composite constriction "Double ETICS" after 5 years from realization. (from left side: synthetic resin plaster (SP) 0,6 cm, mineral wool (MW) $6 \mathrm{~cm}$, mineral rendering (RL) $0,6 \mathrm{~cm}$, original mineral wool $8 \mathrm{~cm}$, original external cladding from lightweight concrete (LC) $24 \mathrm{~cm}$, interior plaster (IP) $1,5 \mathrm{~cm}$ ). According to [13]. 


\section{Experiment for risk assessment}

In the experiment, additional thermal insulation samples will be located directly on the residential house with microorganisms on the original insulation. At least three samples will be located where one will serve as a reference standard for determining the amount and type of microorganisms in the original thermal insulation, the moisture and temperature conditions between the layers. In the other two samples, conservative technology for the elimination of microorganisms will be applied, which should be part of the preparation of the substrate under the application of double thermal insulation. In one of sample, the preparation of the substrate will only be with biocides for remove algae. The other will be cleaned with pressurized water besides to the biocides. After cleaning, sampling will be carried out to determine the amount of mortality of the microorganisms.

A measuring probe will be inserted between the original insulation layer and the new construction layer additional thermal insulation. The Testo 176 P1 - 5 channel pressure recorder will collect the humidity and temperature parameters within the observed period. Upon completion of the data collection, the samples will be dissected, the microorganisms will be collected, and the data will be evaluated for the presence of microorganisms in the composite between the original and the new insulation.

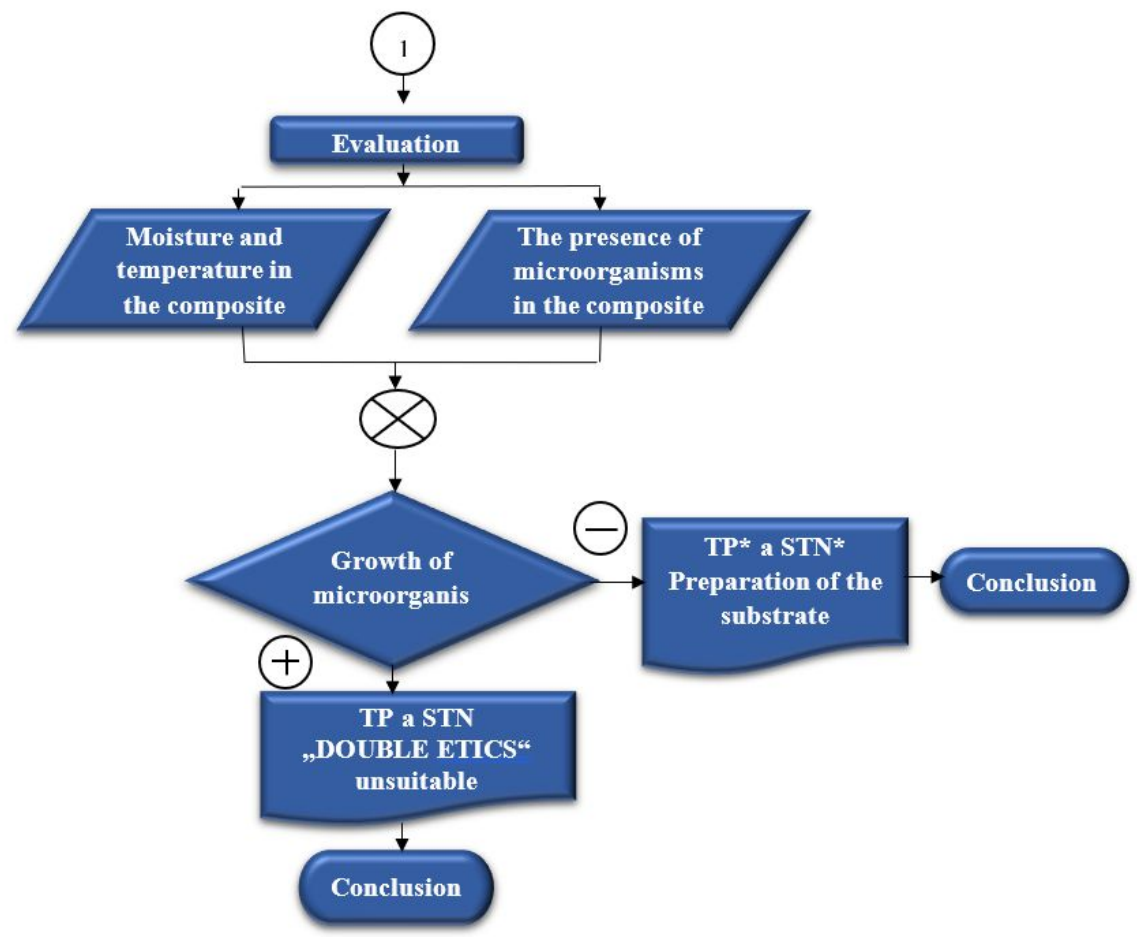

Fig. 3. Flowchart to apply experiment results (authors)

\section{Discussion and conclusion}

It is assumed that the results demonstrate the temperature and humidity conditions appropriate for the development of microorganisms in the set. Using a number of samples that matched mathematical statistics, it is also possible to determine the amount of mortality required by microorganisms to reduce the risk of their development and to ensure the quality of the preparation of the substrate. 
From the evaluation, we expect different results for the group:

- samples A. without preparation of the substrate - without decontamination

- samples B. decontaminating and cleaning with pressurized water

- $\mathrm{C}$ samples with decontamination without cleaning with pressurized water

If the presence of microorganisms in sample A or B is demonstrated in the experiment against the original laboratory sampling, the result will be a proposal to prepare the microorganism substrate prior to application of "Double ETICS" technology. If an increased presence of microorganisms is demonstrated in biocidal and pressurized water samples, the result will be a proposal to exclude the possibility of applying Double ETICS to the biocorrosion-affected surfaces. I assume that a set of information about the actual status of the humidity and temperature conditions in the "Double ETICS" layout can be later used in further studies of the properties of composite thermal insulation or in simulation of the environment in the lifetime research of the double structure.

The experiment is supported by a grant from the Program for the Support of Young Researchers 2018 entitled "Application Research for the Permanent Corrosion of Corrosion on the Surface of Contact Insulation" (AVBIOETICS).

\section{References}

1. E. Barreira, V. Peixoto de Freitas, J. M. P. Q. Delgado, Biol. Defac. of ETICS,1 (2013)

2. J. Švajlenka, M. Kozlovská, T. Pošiváková, Annals of Agricultural and Environmental Medicine, 25 (2018)

3. C. Gaylarde, M. Ribas Silva, Th. Warscheid, Materials and Structures, 36 (2003)

4. E. Barreira, V. Peixoto de Freitas, DBMC,10, 17-20 (2005)

5. R. Steuer: Výskyt řas na vnejším povrchu zateplených budov. (algae occurence on the outer surface of thermally insulated building). Available on https://anzdoc.com/

6. W. Zillig, K. Lenz, K. Sedlbauer, M. Krus, Build. Phys., 2, 14-18 (2003)

7. M. K. Hartwig, M. Krus, C. Fitz, W. Hofbauer, Ch. Scherer, K. Breuer, International Conference XII DBMC, 1, 260-267 (2011)

8. Z. Sternová et al., Principles of design and production of the double ETICS, 3, (2016)

9. STN 73 2901/01, Production of ETICS (2015)

10. STN 73 0540-2: Thermal protection of buildings, Thermal-technical properties building construction and structure. Part 2

11. B. Belániová, D. Lehotská, N. Antošová: CJCE, 3, 7 (2017)

12. Thermal reviews software Svoboda Teplo student edition.

13. M. Krus, D. Rösler: Bauphysik 33 (2011) 